This is the accepted manuscript of the article, which has been published in Social Epistemology. 2017, 31(5), 468-483. https://doi.org/10.1080/02691728.2017.1346722

\title{
Scientific Community: A Moral Dimension
}

\author{
Kristina Rolin \\ Forthcoming in Social Epistemology 31 (5): 468-483.
}

\begin{abstract}
I argue that in epistemically well-designed scientific communities, scientists are united by mutual epistemic responsibilities, and epistemic responsibilities are understood not merely as epistemic but also as moral duties. Epistemic responsibilities can be understood as moral duties because they contribute to the well-being of other human beings by showing respect for them especially in their capacity as knowers. A moral account of epistemically responsible behaviour is needed to supplement accounts that appeal to scientists' self-interests or personal epistemic goals. This is because neither the self-interest nor the epistemic account can always explain why it is rational for an individual scientist to be epistemically responsible.
\end{abstract}

Keywords: Scientific Community; Epistemic Responsibility; Epistemic Cosmopolitanism; Moral Obligations in Science; Cooperation in Science

\section{Introduction}

The social epistemology of scientific knowledge is often understood as a study of the properties of epistemically well-designed scientific communities (Kitcher 1993, 304). Scientific communities are epistemically well-designed when their social practices and institutional arrangements promote the epistemic goals of science, including significant truth (Kitcher 1993) and 
empirical success (Solomon 2001). Social practices and institutional arrangements can promote epistemic goals directly, by conducing towards them, or indirectly, by being connected to some other factor that conduces towards them. For example, a distribution of research efforts is thought to advance the epistemic goals of science indirectly by ensuring that competing theories or methods will receive their share of resources (Kitcher 1990, 1993; Solomon 1992, 2001). A distribution of research efforts is epistemically beneficial in certain phases of inquiry, when it is not yet possible to tell which theory (or theories) will be true or most successful empirically, or which method (or methods) will lead to a breakthrough. When competing theories have different epistemic virtues or when different methods have complementary advantages, it is more reasonable to distribute resources among the theories or the methods, than to allocate all available resources to one theory or method.

I argue that in epistemically well-designed scientific communities, scientists are united by mutual epistemic responsibilities. By epistemic responsibility is meant a duty to be epistemically responsible for one’s knowledge claims to a particular audience. I argue that the duty of epistemic responsibility can promote the epistemic goals of science indirectly by strengthening the social cohesiveness of scientific communities and by facilitating transformative criticism. That the duty of epistemic responsibility plays an epistemically valuable role in scientific communities gives rise to the question of what motivates individual scientists to fulfil their epistemic responsibilities. While epistemically responsible behaviour serves the epistemic goals of science, it may not always help individual scientists achieve their personal epistemic and non-epistemic goals. Epistemically responsible behaviour requires time and effort, and individual scientists may sometimes perceive it as an unnecessary burden.

In order to understand what prompts individual scientists to be epistemically responsible, I introduce three accounts of epistemically responsible behaviour: a self-interest, an 
epistemic, and a moral account. According to the self-interest account, scientists behave in an epistemically responsible way because they believe that it serves their own non-epistemic ends (e.g., career advancement). According to the epistemic account, scientists behave in an epistemically responsible way because they believe that it serves their personal epistemic ends (e.g., the advancement of their own research program). According to the moral account, scientists behave in an epistemically responsible way because they believe that it is their moral duty to do so. Scientists may behave in an epistemically responsible way for any of these three reasons, including a mixture of two or three of them.

My main thesis is that in epistemically well-designed scientific communities, epistemic responsibilities are understood not merely as epistemic but also as moral duties. When epistemic responsibilities are understood as moral duties, they are followed because they are thought to contribute to the well-being of other human beings. I argue also that epistemic responsibilities can be understood as moral duties because they actually serve the well-being of other human beings by showing respect for them especially in their capacity as knowers. By respect is meant the kind of respect that all human beings are owed morally merely because they are human beings, regardless of their social position or individual achievement. The moral account of epistemically responsible behaviour is not meant to replace a self-interest or a purely epistemic account. Rather, it is meant to supplement them. The moral account is needed to bridge the gap between individual scientists' personal ends and the impersonal epistemic ends of science when neither the self-interest nor the epistemic account (or a combination of them) succeeds in explaining why it is rational for an individual scientist to behave in an epistemically responsible way. The upshot is that epistemically well-designed scientific communities are moral communities in the sense that community members are bound together by epistemic responsibilities that can be understood as moral obligations. 
In Section 2, I introduce the duty of epistemic responsibility and explain how it can promote the epistemic goals of science. In Section 3, I argue that a moral account of epistemically responsible behaviour is needed to supplement a self-interest and an epistemic account. In Section 4, I address two concerns about the moral account of epistemically responsible behaviour. One worry is that the moral account is too demanding for most scientists. Another worry is that the universal and impartial nature of moral duties is not compatible with the observation that in the actual practice of science, epistemic responsibilities are often confined to particular scientific communities. In Section 5, I explore further the moral justification of epistemic responsibility.

\section{What Is Epistemic Responsibility?}

While epistemically responsible action is sometimes understood in a broad sense encompassing all actions guided by a desire to have true beliefs (Kornblith 1983, 47), I focus on one category of epistemically responsible actions: the actions of giving reasons with the aim of satisfying the standards of evidence endorsed by a particular audience. A scientist is epistemically responsible in making a knowledge claim when she provides sufficient evidence in its support or adopts a defence commitment with respect to the claim. What counts as sufficient evidence depends on what her main audience is willing to accept without further inquiries or challenges. A defence commitment means that a scientist takes on a duty to defend or revise the claim whenever it is challenged with counter-evidence or some other kind of argument. Thus, epistemic responsibility does not require a scientist to cite evidence in support of all her claims. Insofar as her claims are not challenged, she does not need to defend them. As Michael Williams explains, epistemic justification in this sense is 'like innocence in a court of law: presumptive but in need of defence in the face of contrary evidence' (2001, 25). In this section, I argue that epistemically responsible actions promote 
the epistemic goals of science indirectly by strengthening the social cohesiveness of scientific communities and by facilitating transformative criticism. Both social cohesiveness and transformative criticism are essential to the epistemic success of scientific communities.

My argument is meant to improve on the standard view of scientific communities. According to the standard view, the social cohesiveness of scientific communities is due to shared concepts, beliefs, epistemic values, and epistemic goals (Wray 2007, 344). Community members share many concepts and beliefs because they have undergone similar education and they are familiar with the basic literature on their subject matter of inquiry (Kuhn 1996, 177). It is precisely because community members can take for granted many assumptions about the world and the method of studying the world, that scientific communities are efficient units for conducting scientific research (Wray 2011, 174). However, in order for communities to function efficiently it is not necessary that community members adopt a dogmatic attitude toward their shared assumptions. The assumptions are epistemically justified as long as they are not challenged.

While the concept of scientific community can be applied to various social groups in science, including the community of all scientists, many social epistemologists are concerned with the so called specialty communities. As Thomas Kuhn famously claimed, specialty communities are ‘the producers and validators of scientific knowledge’ $(1996,178)$. Kuhn suggested also that specialty communities can be identified by examining scientists’ citation networks (178). In his view, 'Scientific communities can and should be isolated without prior recourse to paradigms; the latter can then be discovered by scrutinizing the behaviour of a given community’s members' (176). Whereas in sociological literature citation networks are called ‘invisible colleges' (Price and Beaver 1966) or ‘social circles’ (Crane 1969), in philosophical literature they are called 'epistemic interest communities’ (Massey 2014). Uskali Mäki suggests that the concept of specialty community can be extended to cover interdisciplinary communities that have been formed for the purpose of solving a 
complex practical problem (2016, 333). In these communities, scientists may have quite different educational backgrounds; yet, they share an interest in a particular phenomenon (e.g., climate change).

Some science studies scholars have challenged the assumption that specialty communities are the basic organizing units in science. For example, Karin Knorr-Cetina (1982) argues that laboratories and research groups deserve more attention than they have received because they are the sites of knowledge production. In response to this criticism, many social epistemologists have come to recognize the epistemic importance of laboratories and research groups (see e.g., Andersen 2016; Wray 2007). Yet, specialty communities continue to be of interest to social epistemology because they are the sites of knowledge justification, or more accurately, the social practice of knowledge justification. At least ideally, specialty communities provide scientists with arenas where research outputs are scrutinized from a variety of perspectives (Longino 1990, 2002). While individual scientists can conduct research independently and publish individually authored papers, specialty communities control the quality of research by means of training, peer review, criticism, and replication of results (see also Jacobs 2006; Wray 2011). Sabina Leonelli and Rachel Ankeny (2015) suggest that the ability to create and maintain communities is crucial not only to the quality of scientific research but also to the integration of data, methods, and insights across different geographical locations.

In order to improve on the standard view of scientific communities, I argue that the social cohesiveness of scientific communities is due not only to shared concepts, beliefs, epistemic values, and epistemic goals but also to mutual epistemic responsibilities. The duty of epistemic responsibility is based on a particular view of epistemic justification. In this view, epistemic justification is not merely a matter of having reasons for one’s beliefs but also a matter of providing reasons for one’s knowledge claims in a particular social context (see e.g., Reed 2015; Rehg 2009; 
Williams 2001). Given this view of epistemic justification, epistemic justification is always tailored for a particular audience. Yet, a scientist can challenge also the standards of evidence and background assumptions endorsed by her audience. As Helen Longino explains, standards of evidence may be criticized and transformed in reference to other standards, goals, and values held temporarily constant $(2002,131)$.

In the actual practice of science, a scientist fulfils her epistemic responsibilities when, for example, she publishes her research results in a venue that is recognized by her main audience. By communicating her research results in such a venue, she ensures that she has met at least some of the standards of argumentation shared by her audience. A scientist fulfils her epistemic responsibilities also when she responds to a criticism of her views in a forum recognized by her main audience (e.g., a conference, a journal, or some other discussion site for a scientific community). An appropriate response may involve a counter-argument to the criticism or a revision of her views in light of the criticism. In order to carry out her epistemic responsibilities successfully, a scientist needs to make an effort to make her views understandable to her audience.

I argue that in epistemically well-designed specialty communities, scientists are united by mutual epistemic responsibilities because epistemically responsible behaviour strengthens the social cohesiveness of specialty communities and facilitates transformative criticism. Let me explain first why social cohesiveness is epistemically important and how epistemically responsible behaviour contributes to it. Insofar as specialty communities play an important role in the social practice of knowledge justification, their social cohesion is of epistemic interest. While an excessively high level of cohesiveness may give rise to epistemic problems like groupthink (see e.g., Tollefsen 2006), some level of cohesiveness is necessary to give a direction to individual scientists' epistemic activities. Scientists need to have a positive valuation of their community and a 
sense of belonging to it in order to regard the other members of the community as their main audience.

In order to see how epistemically responsible behaviour can strengthen the social cohesiveness of specialty communities, it is important to keep in mind that communities are characterized by a tension between agreement and disagreement. While community members are united by shared concepts, beliefs, epistemic values, and epistemic goals, they can endorse slightly different constellations of these elements, with the consequence that there may not be any unambiguous way to define the boundaries of communities or to distinguish members from nonmembers. Communities may overlap and individual scientists may belong to several communities either simultaneously or in succession (Kuhn 1996, 178). Most importantly, specialty communities are arenas for disagreement and controversy. The disagreement and controversy may concern not only hypotheses, theories, or methods but also what are seen as the community's core concepts, beliefs, and epistemic values (177). Kuhn (1977) warns us against judging such disagreements as necessarily irrational because he thinks that they are essential elements in the development of science (see also Solomon 2001). The duty of epistemic responsibility helps us understand how specialty communities can maintain their social cohesiveness even when community members disagree. When scientists recognize that they have epistemic responsibilities towards other community members, they have a reason to be engaged in a controversy instead of ignoring disagreement or merely tolerating it.

In order to understand why epistemically responsible behaviour is important for specialty communities, it is important to keep in mind also that specialty communities do not form a static social structure of science. As Brad Wray explains, a striking feature of scientific change is that some communities are dissolved while new ones emerge $(2011,117)$. The duty of epistemic responsibility helps us understand how this happens. In principle, vanishing communities could 
have accommodated new discoveries and conceptual changes in a somewhat similar way as those communities that undergo a paradigm change. This means that new discoveries and conceptual changes do not necessarily lead to the fragmentation of scientific communities. The social structure of scientific communities is changed when scientists redirect their epistemic responsibilities from one audience to another.

Epistemically responsible behaviour strengthens also the social cohesiveness of speciality communities by fostering relations of trust among community members. By relations of trust is meant relations where a person A trusts another person B to do something (Frost-Arnold 2013). Relations of trust play an epistemic role when A trusts B to believe and to have good reasons to believe that p, and this is a reason for A to believe that p (Hardwig 1991). That epistemically responsible behaviour is needed to support relations of trust is easy to see especially when scientists fail to be epistemically responsible towards the other members of their communities. As Elizabeth Anderson explains (2011, 146):

“To persist in making certain claims, while ignoring counterevidence and counterarguments raised by others with relevant expertise, is to be dogmatic. To advance those claims as things others should believe on one's say-so, while refusing accountability, is to be arrogant. Dogmatists are not trustworthy, because there is no reason to believe that their claims are based on a rational assessment of evidence and arguments. The arrogant are not trustworthy, because there is reason to believe they are usurping claims to epistemic authority.”

By giving rise to dogmatism and arrogance, epistemically irresponsible behaviour undermines relations of trust among community members, thereby weakening the social cohesiveness of the community. Epistemically responsible behaviour, on the other hand, nurtures 
relations of trust among community members. Relations of trust can contribute to the epistemic success of specialty communities in at least two ways. First, relations of trust can facilitate collaboration among community members, and scientific collaboration enables them to pursue their epistemic goals more effectively than working alone (Wray 2002). Second, relations of trust can give scientists a reason to rely on other scientists as a source of information so that they can cite others’ findings when they seek indirect support for their own results (Hardwig 1991).

So far I have argued that epistemically responsible behaviour promotes the epistemic goals of science by strengthening the social cohesiveness of specialty communities. But this is not the only way in which epistemically responsible behaviour advances the epistemic goals of science. It can bring about epistemic progress also by facilitating transformative criticism within communities as well as across communities. Transformative criticism is conducive to the epistemic goals of science directly when it helps scientists eliminate false beliefs and biased accounts of the subject matter of inquiry, or when it helps them discover significant truths (Longino 1990, 76). And even when criticism does not give scientists a reason to change their views, it can be epistemically valuable by forcing them to provide better arguments for their views or to communicate their views more clearly and effectively. Criticism can help scientists avoid dogmatism.

In sum, I have argued that epistemically responsible behaviour promotes the epistemic goals of science by strengthening the social cohesiveness of specialty communities and by facilitating transformative criticism. However, arguing that epistemically responsible behaviour has epistemically beneficial consequences is one thing, and understanding what actually motivates individual scientists to behave in an epistemically responsible way is another thing. As we cannot expect individual scientists to fully foresee the long-term consequences of their behaviour for scientific communities, we cannot assume that the consequences figure in their motivations to behave in epistemically responsible ways. In the next section, I turn to the question of what might 
cause individual scientists to be epistemically responsible. I argue that a moral account of scientists’ behaviour is needed to complement accounts that appeal to self-interested or epistemic motives.

\section{Coordinating Individual and Community Goals}

When social epistemologists study whether particular social practices or institutional arrangements promote the epistemic goals of science, they are concerned with the impersonal epistemic goals of scientific communities, such as the goal of producing true or empirically adequate accounts of some aspects of reality. While individual scientists may be inspired by impersonal epistemic goals, they are likely to be motivated primarily by their personal goals. As Philip Kitcher explains, individual scientists’ personal goals may be epistemic, non-epistemic, or a mixture of epistemic and non-epistemic considerations (1993, 72). Personal epistemic goals are typically more specific than the impersonal epistemic goals of specialty communities. For example, an individual scientist may aim to understand a particular mechanism or to develop expertise on a particular topic in her specialty. Personal non-epistemic goals may include such aims as career advancement, recognition from peers, or the aim of helping solve urgent social and environmental problems. Kitcher suggests also that epistemic and non-epistemic personal goals easily blur in the actual practice of science (72). This is the case when, for example, a scientist aims not only to describe a particular mechanism but to be the first one to do so because she believes that priority is a means of career advancement.

The distinction between the personal (epistemic and non-epistemic) goals of individual scientists and the impersonal (epistemic) goals of scientific communities gives rise to the question of how the two sets of goals are aligned so that the pursuit of personal goals serves 
impersonal goals instead of undermining them. As Kitcher argues, the gap between personal and impersonal goals - or individual and community goals - is epistemically good (or bad) depending on whether particular kinds of social arrangements succeed (or fail) in making good epistemic use of personal motives (1993, 305). An example of successful coordination is a situation where individual scientists’ personal non-epistemic motivations (e.g., the desire for fame) generate a distribution of research efforts that serves the impersonal epistemic goals of an entire community (see also Solomon 1992, 2001). An example of unsuccessful coordination is a situation where the same personal non-epistemic motivations lead some scientists to produce and disseminate research papers that are based on fraudulent evidence, thereby endangering the epistemic project of an entire community. The coordination of individual and community goals is a pressing problem precisely because individual scientists' personal goals may threaten to undermine the impersonal epistemic goals of scientific communities. ${ }^{1}$

In order to understand what prompts individual scientists to behave in an epistemically responsible way, it is useful to distinguish among three accounts of epistemically responsible behaviour: a self-interest, an epistemic, and a moral account. According to the self-interest account, scientists behave in an epistemically responsible way because they believe that it serves their own non-epistemic ends (e.g., career advancement). According to the epistemic account, scientists

\footnotetext{
${ }^{1}$ By stressing the need to coordinate personal and impersonal goals, I do not claim that scientists' non-epistemic motivations are the main cause of fraud. Nor do I claim that epistemic motivations are the best remedy to the problem of fraud. In an empirical study of the causes of scientific misconduct, Mark Davis, Michelle Riske-Morris, and Sebastian Diaz (2007) argue that causal factors vary greatly from personality factors (e.g., impatience, personal need for recognition) to organizational factors (e.g., insufficient supervision and mentoring, non-collegial work environment).
} 
behave in an epistemically responsible way because they believe that it serves their personal epistemic ends (e.g., a better understanding of a particular mechanism). As Kitcher suggests, it is plausible to assume that scientists are driven in part by considerations of advancing their careers, and in part by considerations of achieving a better understanding (1993, 372). But unlike Kitcher, I do not see a reason to limit an account of scientists' behaviour to a framework in which scientists are seen as either 'sullied' agents (driven by the desire to receive credit for their work), or ‘epistemically pure’ agents (driven by the desire to increase their understanding), or 'mixed-up’ agents (371). There is room for yet another option. According to the moral account, scientists behave in an epistemically responsible way because they believe that it is their moral duty to do so. The moral account differs from the epistemic one because it highlights non-epistemic rather than epistemic reasons. The moral account differs from the self-interest one because the non-epistemic reasons highlighted are different from the ones highlighted by the self-interest account. When scientists act out of moral reasons, they are concerned with the well-being of other human beings and not merely with their own well-being.

I argue that a moral account of epistemically responsible behaviour is needed to supplement a self-interest and a purely epistemic account because there are situations in which neither the self-interest nor the epistemic account (or a combination of them), is sufficient to explain why epistemically responsible behaviour is rational for an individual scientist. In these situations, a moral account is necessary in order to understand why epistemically responsible behaviour is rational not only from the perspective of scientific communities but also from the perspective of individual scientists.

Let me explain first the limitations of the self-interest account of epistemically responsible behaviour. In philosophy of science the self-interest account is advanced by David Hull (1988) who believes that scientists are motivated mainly by their self-interests. As Hull explains, 
'Scientists cooperate to the extent they do because it is in their own self-interest to do so' (1988, 311). In his view, self-interested scientists are guided by the desire for recognition from those members of their communities they themselves regard highly (309). The most important form of recognition that scientists can receive for their work is its use by other members of their communities (309). In the actual practice of science, scientists give recognition to other scientists, for example, by citing their works (310). Citations are often used as a criterion in decisions for funding, promotion, and career advancement. According to Hull, one of the most important features of the social organization of science is that it is not utopian. This means that individual scientists are not expected to sacrifice their self-interests for the larger good (304). Hull has a lot of confidence in scientific communities’ and institutions’ ability to align individual scientists’ self-interested behaviour with the epistemic goals of science so that the former is in the service of the latter. For example, he believes that 'once science is properly understood, it turns out that what is good for the individual scientist is by and large good for science' (304). ${ }^{2}$

I argue that Hull is too optimistic about the ability of scientific communities and institutions to coordinate scientists' self-interested behaviour with the epistemic goals of science. For example, if women's publications are cited regularly at lower rates than men's publications, the reward system of science does not succeed in establishing a systematic connection between epistemically valuable contributions and recognition in the form of citations. And if the reward system of science does not succeed in linking epistemic goods to the non-epistemic goods that selfinterested scientists value highly, we cannot assume that self-interested behaviour will

\footnotetext{
${ }^{2}$ Hull's analysis of scientists as self-interested agents has given rise to models aiming to show that scientists' self-interested behaviour does not compromise the epistemic goals of science. For discussions of the economics approach to social epistemology, see Mäki (2005) and Pinto (2016), and for a more general discussion of game theory, see Amadae (2015).
} 
automatically serve the epistemic goals of science. Marianne Ferber (1988) argues that gender bias has had on impact on citations in labour economics, financial economics, developmental psychology, mathematics, and sociology. She reports that in these fields, references to women's publications constitute a significantly larger proportion of all citations in articles written by women than in articles written by men (82). While Ferber acknowledges that scientific quality, like beauty, is to some extent in the eye of the beholder, she thinks that a systematic gender bias in citations can be revealed in an analysis of relatively large data sets (83). Ferber suggests that men’s tendency to cite women authors at lower rates can be attributed to gendered patterns in scientists' networking (e.g., the persistence of the old boys' networks) rather than to gender differences in research topics or in scientific quality (86).

I regard it as an open empirical question to what extent scientific communities and institutions succeed in organizing their reward systems so that epistemically valuable contributions will receive recognition in the form of citations and career advancement, if not always, at least most of the time. Insofar as it is an open empirical question, we should not assume at the outset that the reward system of science is always successful in coordinating scientists' self-interested behaviour with the epistemic goals of scientific communities.

Besides different forms of bias, the reward system of science is vulnerable to another risk. When the reward system of science relies heavily on financial incentives, its functioning depends on economic and political factors that are beyond the control of scientific communities. This means that whenever the overall funding of scientific research shrinks, the reward system is not capable of delivering bonuses to those scientists who have made epistemically valuable contributions. Even when an individual scientist has succeeded in making an epistemically significant contribution, her epistemic success does not lead to a promotion or an extension of her research grant. For a self-interested agent, this is likely to be a confusing and demoralizing 
experience. It is not my intention to underestimate the importance of funding and properly functioning infrastructure for scientific research. Rather, I suggest that an epistemically and/or morally motivated scientist is able to cope with diminishing research budgets better than her selfinterested colleague. This is because her scientific work is driven not only by financial rewards. I suggest also that it is not wise for scientific communities and institutions to let financial incentives play the main role in their reward systems. This is because a financially driven reward system is dependent on the capricious nature of economy and politics.

The limitations of the self-interest account of scientists' behaviour leads us to consider an epistemic account of epistemically responsible behaviour. According to the epistemic account, scientists behave in an epistemically responsible way because they think that it helps them achieve their personal epistemic goals. One obvious advantage in the epistemic account is that it is relatively easy to see how individual and community goals can be coordinated successfully. Personal epistemic goals are often intermediate goals the achievement of which is one step towards the achievement of impersonal epistemic goals. When this is the case, individual scientists' pursuit of their personal epistemic ends will serve the impersonal epistemic ends of an entire community. Also, when scientists are motivated by epistemic considerations, it is unlikely that they will act in ways that threaten to compromise the epistemic project of an entire community (e.g. fabricate data).

Despite these advantages, the epistemic account has a limitation. When a scientist is preoccupied with her personal epistemic goals, it may be difficult for her to see why she should participate in scientific controversies that will serve mainly the personal epistemic goals of other scientists. Yet, from the point of view of the impersonal epistemic goals of scientific communities, it would be good if she helped other scientists in the pursuit of their personal epistemic goals.

This kind of situation arises when scientists work on research topics that will benefit from cooperation across specialty communities. For example, some archaeologists have made an 
attempt to integrate physical evidence with orally transmitted stories about past events (e.g., flood stories). As Inkeri Koskinen (2016) argues, the use of orally transmitted stories as evidence, or even as clues to evidence, is problematic in the light of folkloristic research. Comparative studies in folkloristics suggest that orally transmitted stories have common elements that can be found in almost any parts of the world. As these elements may have been invented in several places and they may have travelled long distances, they cannot be linked to any specific time and place. Such elements are properly understood as mythical, and it is questionable to treat them as historical evidence (11).

If Koskinen is right in her criticism, cooperation between archaeologists and folklorists who are experts on orally transmitted stories, is in the epistemic interests of science. However, this gives rise to the problem of coordinating scientists’ personal epistemic goals with the impersonal epistemic goals of scientific communities. While archaeologists would clearly benefit from a cooperation with folklorists, the cooperation does not bring about any obvious epistemic benefits to folklorists. An epistemically motivated folklorist may find it satisfying that she has an opportunity to correct a misguided method in another specialty; yet, she will probably ask whether it is worth the time and effort to do so, especially when the alternative is to use her time and energy to advance her own research program. The self-interest account does not help in this case either. Volunteering to offer a critical perspective on archaeologists' research methods may be recognized in an acknowledgement section of a scientific article. But this is hardly the kind of credit that a selfinterested folklorist is looking for. As the reward system of science is organized currently, there are 
no incentives for a self-interested folklorist to attend archaeology conferences or to publish critical discussion notes in archaeology journals (see also Koskinen 2016, 12). ${ }^{3}$

Given the limitations of the epistemic and the self-interest account, I argue that the moral account of epistemically responsible behaviour is needed to explain why it is rational for a folklorist to intervene in another specialty when she does not believe that the intervention will serve her personal epistemic goals or her career advancement. According to the moral account, she will intervene because she thinks that it is her moral duty to do so. As moral motivations are also nonepistemic motivations, someone may raise the concern that moral considerations, like self-interested ones, can undermine the epistemic goals of science. A worrisome scenario is a case in which a morally motivated scientist suppresses evidence because she is afraid that it will reduce the happiness of her audience. In response to this concern, I argue that it is based on a misunderstanding of the moral account. According to the moral account, a morally motivated scientist is concerned with the epistemic abilities of her audience rather than with their happiness. She follows her epistemic responsibilities because she has moral respect for the audience especially in their capacity as knowers. For this reason, a morally motivated scientist would not let happiness trump evidence.

To sum up, I have argued that in some situations cooperation among scientists is in the interests of scientific communities but not in the interests of individual scientists (or at least all the scientists needed for the cooperation). The epistemic account of epistemically responsible behaviour

\footnotetext{
${ }^{3}$ The situation would, of course, change if there were incentives for scholars and scientists to cooperate across disciplines. The rhetoric of interdisciplinarity that can be found in many science policy documents does not necessarily mean that there are incentives for cross-disciplinary cooperation (Mäki 2016).
} 
does not help coordinate individual and community goals when an individual scientist has a hard time of seeing how cooperation will serve her personal epistemic goals. The self-interest account is not helpful when cooperation does not give a scientist the kind of recognition she needs in order to establish herself in their own specialty. The self-interest account may even advise against cooperation if a scientist believes that helping others will give them an advantage in a competition for the same resources. The moral account provides a solution to the problem of coordinating individual and community goals. It can provide a scientist with a reason to cooperate when her epistemic and selfish interests cannot do so. ${ }^{4}$

\section{Moral account of epistemically responsible behaviour}

In this section, I explain why epistemic responsibility can be understood as a moral duty and not merely as an epistemic one. I address two concerns about the moral account. One concern is that the moral account is too demanding for most scientists. Another concern is that the universal and impartial nature of moral duties is in conflict with the observation that in the actual practice of science, epistemic responsibilities are often limited to particular scientific communities.

I argue that the duty of epistemic responsibility can be understood as a moral duty because it actually serves the well-being of other human beings by showing moral respect for them especially in their capacity as knowers. Our capacity to give reasons, to understand reasons, and to

\footnotetext{
${ }^{4}$ In saying this I am concerned with cooperation in the sense of participating actively in scientific communities. What motivates scientists to participate in collaborations in the sense of co-authoring papers is a topic that requires more analysis (see e.g., Frost-Arnold 2013; Wray 2002).
} 
respond to reasons is essential to human value (see also Fricker 2007, 44). Thus, if not all human beings, at least all well-functioning adult human beings are entitled qua human beings to be taken seriously as an epistemic audience. This is a default setting in all social practices of knowledgeseeking, and it is in need of modification only when there is a reason to doubt someone's cognitive capacities or knowledge-seeking intentions.

In order to understand how epistemic responsibility can be both a moral and an epistemic duty, it is useful to visit the distinction between epistemic and moral virtues. As Julia Driver explains, epistemic virtues aim at true or justified beliefs, whereas moral virtues aim at the well-being of other human beings $(2003,105)$. Epistemic virtues such as open-mindedness can, of course, contribute also to the well-being of others, but they do not necessarily aim to do so. Openmindedness is primarily an epistemic virtue because it aims at true or justified beliefs in the person who has the virtue, and this is epistemically valuable even when it does not benefit other human beings. Also, some moral virtues can contribute to true or justified beliefs, but they are primarily moral virtues because the well-being of other human beings is the main source of their value. For example, honesty is primarily a moral virtue because it aims at the well-being of other human beings by creating and supporting relations of trust between the person who has the virtue and her audience (114). This is morally valuable even when honesty does not lead to true or justified beliefs in the person who has the virtue or in her audience.

In a similar way, I argue that epistemic responsibility is an epistemic duty because it aims at justified beliefs in the person who follows the duty as well as in her audience. Epistemic responsibility is also a moral duty because it aims at the well-being of other human beings by showing moral respect for them especially in their capacity as knowers. This is morally valuable even when epistemic responsibility does not lead to true beliefs in the person who follows the duty or in her audience. Epistemic responsibility is a prima facie moral duty, that is, a moral duty that 
may be outweighed by more important moral duties. For example, the moral duty to protect the privacy of people is weightier than the moral duty of epistemic responsibility. This means that a scientist has a moral obligation to protect the privacy of her informants even when sharing detailed information about the informants would be required by her epistemic responsibilities.

It is important to notice that when epistemic responsibilities are understood as moral duties, they are universal in the sense that all knowledge-seekers have them and impartial in the sense that they treat all knowledge-seekers in essentially the same way. The universal and impartial nature of moral duties poses two challenges to the moral account of epistemically responsible behaviour. The first challenge is to understand how the requirements of epistemic responsibility are feasible and reasonable for most scientists. Someone may argue against my view that epistemic responsibilities should not be understood as moral duties because the moral account of epistemically responsible behaviour is too demanding for most scientists. Given the moral account, we all have epistemic responsibilities towards all other human beings (at least insofar as we are engaged in knowledge-seeking practices). In order to fulfil our epistemic duties towards other human beings, we should be able to meet the standards of evidence endorsed by various audiences. As the standards of evidence may vary greatly from one audience to another, this task is almost impossible to carry out successfully. Indeed, it is not clear whether anyone can actually live up to the requirements of epistemic responsibilities if they are understood as universal and impartial moral duties. This means also that most scientists will not be able to fulfil their epistemic responsibilities even if they wish to do so.

The second challenge is closely connected to the first one. The challenge is to understand how the universal and impartial nature of moral duties is compatible with the observation that in the actual practice of science, epistemic responsibilities are understood as local and partial. Most of the time scientists behave as if they have epistemic responsibilities primarily towards the members of their communities. Scientists sometimes respond to criticism coming from 
other audiences but they do not address these audiences on a regular basis. Similarly, they sometimes give a talk to a larger audience but for obvious reasons, such as lack of time and other resources, they do not attempt to communicate all their views to all audiences. They often ignore those audiences who they think do not have the competence to contribute to scientific research.

In order to respond to the two challenges, it is necessary to visit cosmopolitan moral philosophy. I suggest that epistemic responsibilities, like other moral duties, can be understood as either general or special moral duties. As Robert Goodin explains, general moral duties are the duties we have towards other human beings merely because they are human beings, and special moral duties are the duties we have towards particular individuals because they stand in some special relation to us $(1988,663)$. The term 'general' is meant to suggest that general moral duties are universal and impartial. Special moral duties are local and partial. As Goodin explains (665):

'Whereas our general duties tell us how we should treat anyone, and are hence the same toward everyone, special duties vary from person to person. In contrast to the universality of the general moral law, some people have special duties that other people do not. In contrast to the impartiality of the general moral law, we all have special duties to some people that we do not have to others.'

Relations among family members, friends, and fellow countrymen are examples of special relations that are thought to involve special moral duties.

Goodin is concerned with the question of where special moral duties come from and how they fit together with general moral duties. According to his cosmopolitan moral philosophy, special moral duties are essentially distributed general moral duties $(1988,678)$. They are created by assigning general moral duties to particular human beings standing in particular relations. This means also that the moral force of special moral duties is derived from the moral force of general 
moral duties (679). To defend cosmopolitanism, Goodin argues that in many cases the most efficient way to implement general moral duties is to assign them to particular people standing in particular relations thereby creating a division of moral labour. In some cases, a distribution of moral duties is the only way to implement general moral duties because some of them are too demanding for some human beings.

Let me use Goodin's example to illustrate this claim. People who happen to be on a beach on a particular day all have a general moral duty to rescue a person who is in danger of drowning. For many reasons not all persons on the beach are actually capable of carrying out this duty. If they all attempted to meet the duty to rescue the person in the water, the outcome would be a chaotic situation where more than one person is in danger of being drowned. A better way to implement a general moral duty is to assign it to a person who is well suited for the task of rescuing people in water: the lifeguard. When a general moral duty is assigned to a particular person standing in a particular relation, it gives rise to a special moral duty that the person has. Thus, the lifeguard has a special moral duty to help people in life-threatening situations on the beach.

In Goodin's analysis, special moral duties are morally justified insofar as they are distributed general moral duties. He does not deny that voluntary agreements play a role in the generation of special moral duties. The assignment of a moral duty to a particular person standing in a particular relation (e.g., the lifeguard on duty) is based on the person's voluntary agreement to sign on for the role and the duties that come with the role. However, voluntary agreements can play a role merely in the distribution of moral duties but not in the justification of moral duties. The special moral duty the lifeguard has is morally binding because it is ultimately based on a general moral duty.

Goodin’s account of special moral duties as distributed general moral duties implies also that some people bear a primary responsibility for a particular moral duty whereas some others 
bear merely a secondary responsibility. When the moral duty to help a person in a life-threating situation has been assigned to the lifeguard, the lifeguard has a primary responsibility to see that no one is drowned, with the consequence that the other parties are released from a primary responsibility to so do. However, the other parties still have a secondary responsibility to look after the safety of other people on the beach. This means that if the lifeguard is not up to his or her task, then the others will have to pick up the primary responsibility for the duty.

Building on Goodin’s argument, I suggest that the epistemic responsibilities scientists have towards the other members of their communities can be understood as special moral duties. I call them special epistemic responsibilities to distinguish them from general epistemic responsibilities. Whereas general epistemic responsibilities are universal and impartial, special epistemic responsibilities are limited to special relations, such as relations among the members of particular epistemic communities. That special epistemic responsibilities are local and partial means that scientists can legitimately give a priority to the community's standards of evidence and the objections coming from the community. However, this is the case only as long as a particular division of epistemic labour prevails. If the division of epistemic labour is challenged (on the grounds that it no longer serves the epistemic goals of science), then scientists may have to reconsider towards whom they have special epistemic responsibilities.

In order to explain how general and special epistemic responsibilities can co-exist without conflicts, I introduce a view I call epistemic cosmopolitanism. ${ }^{5}$ Epistemic cosmopolitanism is an epistemic application of Goodin's cosmopolitan account of special moral duties. Epistemic cosmopolitanism states that (a) insofar as we are engaged in knowledge-seeking practices, we have general epistemic responsibilities, and (b) the special epistemic responsibilities scientists have as

\footnotetext{
${ }^{5}$ The version of epistemic cosmopolitanism I defend here is a revised version of the one I have discussed in Author (XXXX).
} 
members of scientific communities are essentially distributed general epistemic responsibilities. Epistemic cosmopolitanism enables me to respond to the two concerns about the moral account of epistemically responsible behaviour. When special epistemic responsibilities are understood as distributed general epistemic responsibilities, the tension between the two disappears. The universal and impartial nature of general epistemic responsibilities is not in conflict with the local and partial nature of special epistemic responsibilities when the latter are seen as a means to implement the former. By following one’s special epistemic responsibilities, one fulfils one’s share of general epistemic responsibilities.

In response to the worry that the moral account is too demanding, I argue that a division of epistemic labour is a key to understanding how the demands of general epistemic responsibilities can be transformed into requirements that are feasible and reasonable for most scientists. General epistemic responsibilities are no longer overwhelming when they are distributed to particular human beings standing in particular relations thereby generating special epistemic responsibilities. One could even argue that in epistemically well-designed scientific communities, no scientist is put into a position where she is not capable of carrying out her special epistemic responsibilities. That the requirements of special epistemic responsibilities should be feasible and reasonable for individual scientists may in part explain why some scientific communities are fragmented thereby giving rise to novel specialty communities (see also Price 1986). The explanation may be that special epistemic responsibilities are attainable in the emerging specialty communities, whereas scientists' special epistemic responsibilities in the fragmented communities have become too burdensome.

In sum, I have argued that scientific communities can be understood moral communities in the sense that community members are united by special epistemic responsibilities. That scientists have special epistemic responsibilities as members of scientific communities helps us understand why most scientists behave so that they give priority to one audience. I have argued 
that their behaviour is justified in the light of their special epistemic responsibilities, and their special epistemic responsibilities are justified in the light of their general epistemic responsibilities. However, special epistemic responsibilities may change when an existing division of epistemic labour is challenged.

This will lead me back to the example discussed in the previous section. As the division of epistemic labour is understood currently, a folklorist does not have special epistemic responsibilities towards archaeologists; her special epistemic responsibilities lie primarily in her own speciality community. However, an existing division of epistemic labour can be challenged on the grounds that it does not serve the impersonal epistemic goals of scientific communities. If the cooperation between archaeologists and folklorists is in the epistemic interests of science, a division of epistemic labour should be changed so that, at least in some cases, archaeologists and folklorist should have mutual special epistemic responsibilities. This is the basis for claiming that a folklorist has a moral obligation to intervene in the problematic use of orally transmitted stories in archaeology.

\section{Epistemic Contractarianism versus Cosmopolitanism}

In Section 2, I have argued that the duty of epistemic responsibility can promote the epistemic goals of science indirectly by strengthening the social cohesiveness of scientific communities and by facilitating transformative criticism. This gives an epistemic justification to the duty of epistemic responsibility. Insofar as epistemic responsibility is also a moral duty, we need to be concerned with its moral justification. In Section 4, I have argued that (i) the moral justification for general epistemic responsibilities lies in the view that human value in itself requires us to take others seriously as an epistemic audience, and (ii) the moral justification for special epistemic 
responsibilities flows from the moral justification of general epistemic responsibilities. I have called this view epistemic cosmopolitanism. In this section, I defend epistemic cosmopolitanism against a possible objection.

A possible objection to epistemic cosmopolitanism is that there is an alternative and equally plausible account of the moral justification of special epistemic responsibilities. What I call epistemic contractarianism is the view that the moral force of special epistemic responsibilities is derived from a voluntary agreement to become a member of a particular scientific community (and such an agreement can take place independently of whether there are or are not general epistemic responsibilities). While epistemic cosmopolitanism acknowledges that scientific communities are based on voluntary membership, it differs from epistemic contractarianism in that the moral force of special epistemic responsibilities is derived from general epistemic responsibilities, not merely from voluntary agreements. In what follows, I argue that epistemic cosmopolitanism is a superior view to epistemic contractarianism.

At first sight, epistemic contractarianism appears to be a plausible position because it resonates with the standard view of scientists' moral obligations. According to the standard view, scientists have both general obligations as human beings and role obligations as scientists. Whereas general obligations are justified in the light of general moral theories, role obligations owe their justification to scientists' voluntary accepting their role and the obligations that come with the role. According to the standard view, role obligations do not come with reductions of general obligations. As Heather Douglas explains, role obligations are layered on top of general obligations $(2014,971)$.

According to Michael Hardimon, a role obligation is a moral requirement 'which attaches to an institutional role, whose content is fixed by the function of the role, and whose normative force flows from the role' $(1994,334)$. While some role obligations are non-contractual, contractual role obligations are the ones which are acquired by 'signing on for the roles from which 
they derive' (354). In signing on for a role, one agrees to carry out the duties of the role (356). Hardimon suggests that in some cases 'signing on for a role' should be understood to mean that one identifies with the role, and the role identification is the source of reasons and motivations to carry out the role obligations (358). Yet, Hardimon emphasizes that roles and the obligations attached to them are not fully in the control of the person who has voluntarily signed on for them. As he explains, social roles are institutionally defined structures of rights and duties (354).

In epistemic contractarianism, the special epistemic responsibility a scientist has as a member of a scientific community is understood to be a contractual role obligation. Also, it is the voluntary nature of the agreement to sign on for the role that is responsible for the moral force of the role obligation. The voluntary agreement has to be done by the person whose obligation it is. Mere social expectations are not sufficient to generate morally binding role obligations. The agreement to become a member of a scientific community may of course be something that takes place tacitly and over time (see also Hardimon 1994, 363).

I do not deny that scientists have contractual role obligations and that these obligations play an important role in research ethics. Yet, I argue that special epistemic responsibilities are not contractual role obligations. And therefore, epistemic contractarianism is not a tenable position.

One problem in epistemic contractarianism is that it cannot explain how general epistemic responsibilities can be converted into doable and bearable requirements. This is because voluntary agreements cannot lighten the burden of general epistemic responsibilities. Voluntary agreements can merely generate role obligations that are added on top of general obligations. For example, a manager cannot argue plausibly that she has no moral obligations towards other citizens because she has voluntarily entered a contract with a company and this contract involves a moral duty to look after the interests of the shareholders of the company. The argument is not plausible 
because the manager has general moral obligations towards other citizens, and the role obligations she has as a manager are added on top of her general moral obligations.

Another problem in epistemic contractarianism is that it grants too much moral weight to voluntary agreements. If we accept the view that voluntary agreements can create contractual role obligations, then we are bound to accept the highly problematic view that voluntary agreements can give justification for obligations that run against our other moral duties. For example, let us assume that a person has voluntarily agreed to become a member of a racist organization and the other members of the organization expect her to be loyal to the organization. If we accept the view that voluntary agreements can create contractual role obligations, then we have to admit that the person has a genuine moral duty to be loyal to the organization. This conclusion is in conflict with the view that the person, like all of us, has a moral duty to treat all human beings with respect and to recognize their equal human value.

I suggest that the conflict between the person's contractual role obligations and general obligations is generated by giving too much moral weight to voluntary agreements. The conflict can be avoided by abandoning the view that the moral force of contractual role obligations is derived solely from voluntary agreements. Insofar as contractual role obligations are morally justified, there has to be another source of moral justification besides voluntary agreements. The roles that people accept voluntarily have to be morally acceptable in the first place in order to generate genuine moral duties (see also Jeske 2014; Scheffler 2001). A voluntary membership in a racist organization does not create genuine moral duties simply because both the organization and the role are without moral justification.

In sum, I have argued that epistemic contractarianism is an untenable position for two reasons, one being that it cannot reduce the burden of general epistemic responsibilities, and another one being that it grants too much moral force to voluntary agreements. Epistemic cosmopolitanism 
avoids both of these two problems. When special epistemic responsibilities are understood as distributed general epistemic responsibilities, they lighten the burden of general epistemic responsibilities, that is, the epistemic responsibilities scientists have towards all other human beings merely in virtue of participating in knowledge-seeking practices. Epistemic cosmopolitanism avoids also the other problem in epistemic contractarianism, the problem that it grants too much moral force to voluntary agreements. When special epistemic responsibilities are understood as distributed general epistemic responsibilities, their moral justification is derived from the moral justification of general epistemic responsibilities. It is not derived merely from a voluntary agreement to be a member of a particular scientific community.

\section{Conclusion}

That scientific communities are epistemic communities is self-evident. That they are moral communities is not self-evident. I have argued that epistemically well-designed scientific communities are moral communities in the sense that community members have epistemic responsibilities vis-à-vis other community members. A moral account of epistemically responsible behaviour is needed to complement the view that scientists are motivated by their self-interests or their own epistemic ends. A moral account suggests that scientists behave in an epistemically responsible way because they believe that it is their moral duty to do so. When epistemic responsibilities are understood as moral duties, they are followed because they are believed to contribute to the well-being of other human beings. This means also that epistemic responsibilities are universal and impartial in the sense that they transcends any particular epistemic community. Yet, we have epistemic responsibilities only insofar as we are engaged in knowledge seekingpractices. 
I have introduced a view I call epistemic cosmopolitanism to explain how the universal and impartial nature of moral duties is compatible with the observation that epistemic responsibilities are often confined to particular epistemic communities. The tension between the universal and impartial nature of general epistemic responsibilities and the local and partial nature of special epistemic responsibilities disappears as soon as we realize that special epistemic responsibilities can be understood as distributed general epistemic responsibilities. A division of epistemic labour is a key to understanding that general epistemic responsibilities need not be too demanding for most human beings. General epistemic responsibilities can be converted into feasible and reasonable requirements by distributing them so that some human beings have epistemic responsibilities towards some audiences and some others towards some other audiences.

Epistemic cosmopolitanism has an interesting implication to our views concerning the relations between scientific communities and lay communities. The epistemic responsibilities scientists have towards the other members of their communities are not radically different from the epistemic responsibilities they have towards other human beings. The reason for this is that in both cases, scientists’ epistemic responsibilities are distributed general epistemic responsibilities. From a moral point of view, they are made of the same stuff. This means also that a voluntary agreement to join one epistemic community does not give one a permission to sign off from one's epistemic responsibilities towards other epistemic communities. That scientists' epistemic responsibilities are often confined to particular epistemic communities is merely a matter of maintaining an efficient division of epistemic labour.

Acknowledgements: I wish to thank the two reviewers of Social Epistemology for their comments on earlier versions of the manuscript. 


\section{References}

Amadae, S. M. 2015. Prisoners of reason: Game theory and neoliberal political economy. New York: Cambridge University Press.

Andersen, H. 2016. “Collaboration, interdisciplinarity, and the epistemology of contemporary science.” Studies in History and Philosophy of Science 56: 1-10.

Anderson, E. 2011. “Democracy, public policy, and lay assessment of scientific testimony.” Episteme 8 (2): 144-164.

Crane, D. 1969. "Social structure in a group of scientists: A test of the 'invisible college' hypothesis.” American Sociological Review 34 (3): 335-352.

Davis, M. S., M. Riske-Morris, and S. R. Diaz. 2007. “Causal factors implicated in research misconduct: Evidence from ORI case files.” Science and Engineering Ethics 13: 395-414.

Douglas, H. 2014. “The moral terrain of science.” Erkenntnis 79 (5): 961-979. 
Driver, J. 2003. “The conflation of moral and epistemic virtue.” In Moral and epistemic virtues, edited by M. Brady and D. Pritchard, 101-116. Malden, Oxford, Carlton: Blackwell Publishing.

Ferber, M. 1988. “Citations and networking.” Gender \& Society 2 (1): 82-89.

Fricker, M. 2007. Epistemic injustice: Power \& the ethics of knowing. Oxford and New York: Oxford University Press.

Frost-Arnold, K. 2013. “Moral trust \& scientific collaboration.” Studies in History and Philosophy of Science 44: 301-310.

Goodin, R. 1988. “What is so special about our fellow countrymen?” Ethics 98 (4): 663-686.

Hardimon, M. 1994. “Role obligations.” Journal of Philosophy 91 (7): 333-363.

Hardwig, J. 1991. “The role of trust in knowledge.” Journal of Philosophy 88 (12): 693-708.

Hull, D. L. 1988. Science as a process. Chicago: The University of Chicago Press. 
Jacobs, S. 2006. "Models of scientific community: Charles Sanders Peirce to Thomas Kuhn.” Interdisciplinary Science Reviews 31 (2): 163-173.

Jeske, D. 2014. “Special obligations.” The Stanford Encyclopedia of Philosophy (Spring 2014 Edition), Edward N. Zalta (ed.), URL = <http://plato.stanford.edu/archives/spr2014/entries/specialobligations/>.

Kitcher, P. 1990. “The Division of Cognitive Labor.” The Journal of Philosophy 87 (1): 5-22.

Kitcher, P. 1993. The Advancement of science: Science without legend, objectivity without illusions. New York and Oxford: Oxford University Press.

Knorr-Cetina, K. 1982. "Scientific communities or transepistemic arenas of research? A critique of quasi-economic models of science.” Social Studies of Science 12: 101-130.

Kornblith, H. 1983. “Justified belief and epistemically responsible action.” The Philosophical Review XCII (1): 33-48.

Koskinen, I. 2016. "Where is the epistemic community? On democratisation of science and social accounts of objectivity.” Synthese doi: 10.1007/s11229-016-1173-2. 
Kuhn, T. 1977. “Objectivity, value judgment, and theory choice.” In The essential tension: Selected studies in scientific tradition and change, 320-339. Chicago: The University of Chicago Press.

Kuhn, T. 1996. The structure of scientific revolutions. Third ed. Chicago: The University of Chicago Press.

Leonelli, S. and R. Ankeny. 2015. "Repertoires: How to transform a project into a research community.” BioScience 65 (7): 701-708.

Longino, H. 1990. Science as social knowledge. Princeton: Princeton University Press.

Longino, H. 2002. The fate of knowledge. Princeton: Princeton University Press.

Massey, T. 2014. "Structuralism and quantitative science studies: Exploring first links.” Erkenntnis 79: 1493-1503.

Mäki, U. 2005. “Economic epistemology: Hopes and horrors.” Episteme 1 (3): 211-222. 
Mäki, U. 2016. “Philosophy of interdisciplinarity. What? Why? How?” European Journal for Philosophy of Science 6 (3): 327-342.

Pinto, M. F. 2016. "Economics imperialism in social epistemology: A critical assessment.” Philosophy of the Social Sciences 46 (5): 443-472.

Price, D. 1986. [1963]. Little science, big science ... and beyond. New York: Columbia University Press.

Price, D., and D. Beaver. 1966. “Collaboration in an invisible college.” American Psychologist 21 (11): 1011-1018.

Reed, B. 2015. “Reasons for reasons.” Episteme 12 (2): 241-247.

Rehg, W. 2009. Cogent science in context: Science wars, argumentation theory, and Habermas. Cambridge and London: The MIT Press.

Scheffler, S. 2001. Boundaries and allegiances: Problems of justice and responsibility in liberal thought. Oxford and New York: Oxford University Press. 
Solomon, M. 1992. "Scientific rationality and human reasoning.” Philosophy of Science 59 (3): 439-455.

Solomon, M. 2001. Social empiricism. Cambridge: MIT Press.

Tollefsen, D. P. 2006. “Group deliberation, social cohesion, and scientific teamwork: Is there room for dissent?” Episteme 3 (1-2): 37-51.

Williams, M. 2001. Problems of knowledge: A critical introduction to epistemology. Oxford and New York: Oxford University Press.

Wray, K. B. 2002. “The epistemic significance of collaborative research.” Philosophy of Science 69 (1): 150-168.

Wray, K. B. 2007. “Who has scientific knowledge?” Social Epistemology 21 (3): 337-347.

Wray, K. B. 2011. Kuhn's evolutionary social epistemology. Cambridge: Cambridge University Press. 